status. ${ }^{4}$ Determination of the exact timing, however, remains difficult. Monitoring of PAP, pulmonary capillary wedge pressure, and LV function before and during the weaning process is mandatory. ${ }^{4}$

We report the case of a young man with idiopathic pulmonary arterial hypertension who underwent urgent BLTx for decompensation. We attribute his complicated postoperative course to diastolic dysfunction in a chronically deprived LV in combination with an increased preload, resulting from normalization of the PVR, and an increased afterload during weaning. Awareness of this problem may lead to earlier discrimination of such patients and a more controlled weaning process after BLTx.
We thank Piet Claus and Maja Cikes for their valuable help regarding the analysis of echocardiographic images.

\section{References}

1. Vizza CD, Lynch JP, Ochoa LL, Richardson G, Trulock EP. Right and left ventricular dysfunction in patients with severe pulmonary disease. Chest. 1998;113: 576-83.

2. Kerstein D, Levy PS, Hsu DT, Hordof AJ, Gersony WM, Barst RJ. Blade balloon atrial septostomy in patients with severe primary pulmonary hypertension. Circulation. 1995;91:2028-35

3. Koeken Y, Kuijpers NH, Lumens J, Arts T, Delhaas T. Atrial septostomy benefits severe pulmonary hypertension by increase of left ventricular preload reserve. Am J Physiol Heart Circ Physiol. 2012;302:H2654-62.

4. Bîrsan T, Kranz A, Mares P, Artemiou O, Taghavi S, Zuckermann A, et al. Transient left ventricular failure following bilateral lung transplantation for pulmonary hypertension. J Heart Lung Transplant. 1999;18:304-9.

\title{
Esophageal complications of catheter ablation for atrial fibrillation: A case report
}

\author{
Eitan Podgaetz, MD, MPH, ${ }^{\mathrm{a}}$ and Claude Deschamps, MD, ${ }^{\mathrm{b}}$ Boston, Mass, and Rochester, Minn
}

Atrial fibrillation is the most common cardiac arrhythmia. It is commonly known as irregularly irregular because the time elapsing between 2 consecutive $\mathrm{R}$ waves do not follow a repetitive pattern and there are no distinct $P$ waves.

Atrial fibrillation has significant morbidity and associated health care costs. Many medical and nonmedical treatments exist to control atrial fibrillation. Catheter ablation of atrial fibrillation foci is a relatively new technology to manage atrial fibrillation in selected patients.

Minimally invasive techniques in all fields of surgery and medicine have blossomed with new technology and increased patient interest. Long-term results are lacking and new potential complications related to the new technologies are now being seen.

Catheter-based therapies for atrial fibrillation are part of the current guidelines recommended by major international cardiovascular societies. ${ }^{1}$

Since the initial report by Haïnsaguerre and colleagues ${ }^{2}$ of pulmonary vein foci as initiators of atrial fibrillation in 1998, many developments have been made to ablate these foci to eradicate atrial fibrillation. Long-term follow-up

\footnotetext{
From the Division of Thoracic Surgery, ${ }^{\mathrm{a}}$ Massachusetts General Hospital, Boston, Mass; and the Division of Thoracic Surgery, ${ }^{\mathrm{b}}$ Mayo Clinic, Rochester, Minn. Disclosures: Authors have nothing to disclose with regard to commercial support. Received for publication Aug 26, 2012; accepted for publication Oct 15, 2012; available ahead of print Nov 12, 2012.

Address for reprints: Eitan Podgaetz, MD, MPH, 7 Emerson Pl, No. 702, Boston, MA, 02114 (E-mail: epodgaetz@partners.org)

J Thorac Cardiovasc Surg 2013;145:e9-13

$0022-5223 / \$ 36.00$

Copyright (C) 2013 by The American Association for Thoracic Surgery http://dx.doi.org/10.1016/j.jtcvs.2012.10.022
}

and potential complications from many of these advanced techniques are unknown.

Circumferential pulmonary vein and left atrial ablation is reported to be effective for paroxysmal and chronic atrial fibrillation. ${ }^{3-5}$ In the 2011 focused update on the management of patients with atrial fibrillation, the American College of Cardiology, American Heart Association, and the European Society of Cardiology continue to recommend ablation therapies to manage atrial fibrillation. ${ }^{1}$

The technique for catheter ablation varies by institution and among electrophysiologists. Commonly, the procedure is performed using transesophageal echocardiogram to rule out the presence of atrial thrombi and assess ventricular and valvular function. An electrode catheter in the coronary sinus is used to record left atrial electrical activity as well as for pacing. After transseptal puncture, patients are anticoagulated with the aim to maintain an activated clotting time of 300 seconds or greater. Different devices exist to create lesions around the pulmonary veins, usually 1 to $2 \mathrm{~cm}$ from their ostia, along the posterior left atrium or roof and along the mitral isthmus. ${ }^{6}$ Catheter ablation for atrial fibrillation has a reported morbidity of approximately $6 \%{ }^{7}$

Major complications after catheter ablation for atrial fibrillation have been reported in the cardiology, radiology, and surgical literature. ${ }^{8-12}$ Factors identified as risk factors for complications include multiple transseptal punctures, prolonged and complicated sheath, catheter manipulations, and aggressive attempts at transmural ablation (high energy and high contact forces). The most common complication reported are pulmonary vein stenosis $(1.63 \%)$, pericardial 


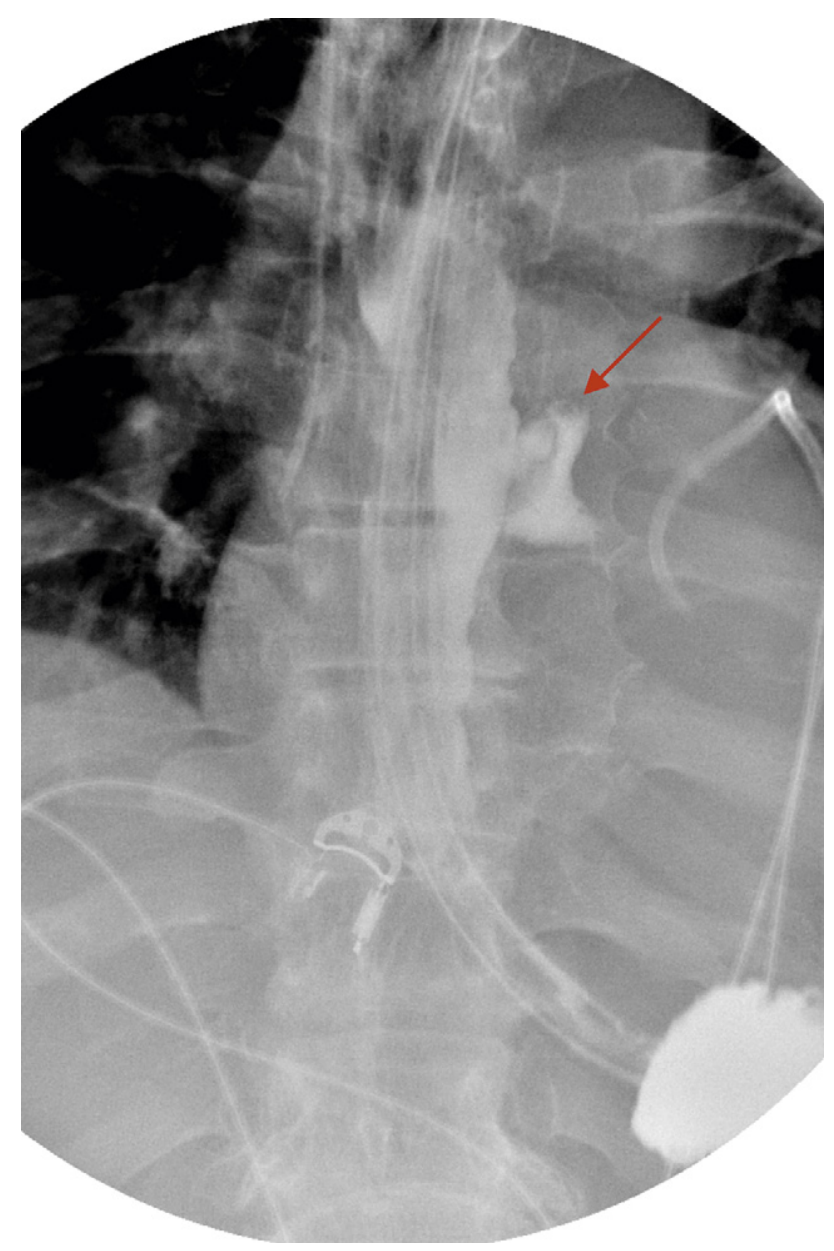

FIGURE 1. Gastrografin esophagogram showing a contained leak (arrow).

tamponade $(1.22 \%)$, neurologic complications (eg, stroke and transient ischemic attack) $(0.94 \%)$, esophageal injury (ie, atrioesophageal fistula) $(<0.25 \%)$, and phrenic nerve injury $(0.11 \%){ }^{13}$

\section{CLINICAL SUMMARY}

A 71-year-old man with a significant past medical history for paroxysmal atrial fibrillation, hypertension, dyslipidemia, and obstructive sleep apnea recently underwent radio frequency ablation around the pulmonary veins to treat atrial fibrillation at an outside hospital. He was prescribed the anticoagulant warfarin and discharged from the hospital the day after his procedure. Five days after discharge he returned with a large right groin hematoma that was managed conservatively; pseudoaneurysm was ruled out. Two weeks later, after eating breakfast, he experienced excruciating chest and back pain radiating to his left shoulder. He presented to his local emergency department where he was diagnosed with hypotension and tachycardia. His evaluation included a chest $\mathrm{X}$-ray film and a computed tomography scan of his chest showing pneumopericardium and pneumomediastinum with oral contrast extravasation from his esophagus to his pericardium. He was admitted to the intensive care unit where he required vasopressor agents; a pericardial drain was placed yielding $>400 \mathrm{~mL}$ viscous yellow aspirate that was positive for Gram positive rods with immediate relief of his tamponade physiology. His leukocyte count was $8.1 \mathrm{th} / \mathrm{cmm}$, hemoglobin $10.9 \mathrm{gm} / \mathrm{dL}$, and platelets $309 \mathrm{th} /$ cumm. He was placed on broad-spectrum antibiotics and was transferred to our institution for definite management.

On our initial assessment he was afebrile, tachycardic to $100 \mathrm{bpm}$ in sinus rhythm, with blood oxygen saturation $94 \%$ on $4 \mathrm{~L}$ nasal cannula. He appeared to be anxious and uncomfortable but in no acute distress. Physical examination showed that he had bilateral breath sounds clear to auscultation and mediastinal dullness. He was warm and well perfused without taking any vasopressor agents. A repeat esophagogram performed at our institution showed a focal contained leak to the left of the distal esophagus 10 to $14 \mathrm{~cm}$ proximal of the esophagogastric junction (Figure 1).

Lower extremity duplex ruled out deep vein thrombosis and a bedside echocardiogram ruled out air within the left atrium. A subsequent esophagoduodenoscopy was performed by one of our advance endoscopists. Minimal insufflation revealed a small, 2- to 3-mm thermal burn $35 \mathrm{~cm}$ from the incisors without evidence of a fistulous tract. A fully covered self-expandable metal stent (SEMS) (proximal and distal flanges 28 and $23 \mathrm{~mm}$ ) was placed over a wire and under direct visualization.

A subsequent chest x-ray film showed stent migration for which another endoscopy was performed and the fully covered SEMS was removed and a partially covered SEMS was placed (Ultraflex esophageal stent; Boston Scientific, Natick, Mass) (28/23 mm diameter, $12 \mathrm{~cm}$ long, $9 \mathrm{~mm}$ covered).

During recovery the patient was diagnosed with acalculous cholecystitis by ultrasound and computed tomography scan. The symptoms were resolved when a percutaneous cholecystostomy tube was placed. A new swallow study showed a persistent leak around the esophageal stent (Figure 2). At this point our endoscopist performed an overlapping stent-in-stent approach to control the leak. The attempt was determined to be unsuccessful because the pooled contrast seen in a swallow study refluxed around the stent, showing evidence of a persistent leak. Both overlapping stents were removed and the patient was taken to the operating room.

\section{OPERATIVE APPROACH}

In the right lateral decubitus position, a left posterolateral thoracotomy though the fifth intercostal space was performed. Moderate intrapleural contamination was found, and the inferior pulmonary ligament was taken down with 


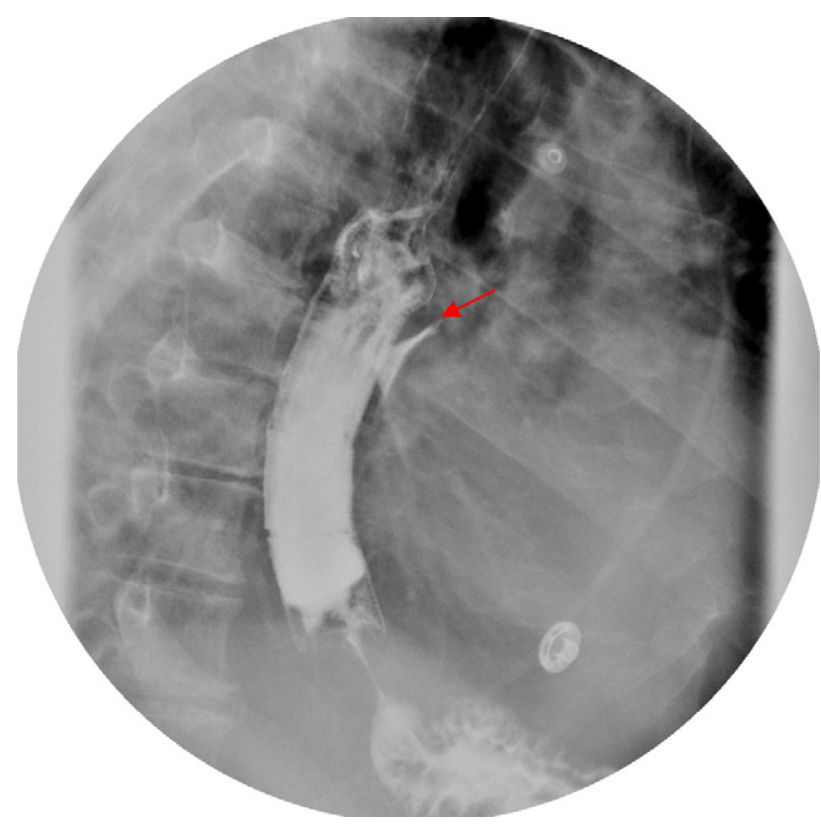

FIGURE 2. Gastrografin esophagogram showing a contained leak around the self-expandable metal stent (arrow).

electrocautery. The esophagus was dissected cephalad from the diaphragmatic hiatus until the fistulous communication with the pericardium was identified and then beyond for another $3 \mathrm{~cm}$. The fistula was taken down sharply. The esophageal perforation was clearly defined, measuring $3 \mathrm{~mm}$ in size (Figure 3). The pericardium was debrided and no definite atrial opening was identified. The esophageal perforation was oversewn in 2 layers with nonabsorbable suture material and an autologous pericardial patch was used to buttress the repair. A surgical drain and a single chest tube were placed. The patient tolerated the procedure well.

The patient's postoperative course was unremarkable. Postoperative swallow study on postoperative day 6 showed no evidence of leak. His diet was advanced and he was discharged from the hospital on postoperative day 12 .

\section{DISCUSSION}

Esophageal injuries after catheter ablation for atrial fibrillation are rare, with the exact incidence ranging from $0.05 \%$ to $1.5 \% .{ }^{14-16}$ The first case report found in the international literature appeared in $2001 .{ }^{17}$ Since then a total of 50 case reports, mostly single cases, were found during our literature search (Table 1). ${ }^{5,7,9,11,14-32}$ The more common presenting symptoms are fever, chills, chest pain, hypotension, and transient or permanent neurologic events.

Typically, an emergency medicine physician initially evaluates the patient. Computed tomography scans, swallow studies, and echocardiograms are commonly obtained during initial evaluation. Signs of unusual chest pain, sepsis,

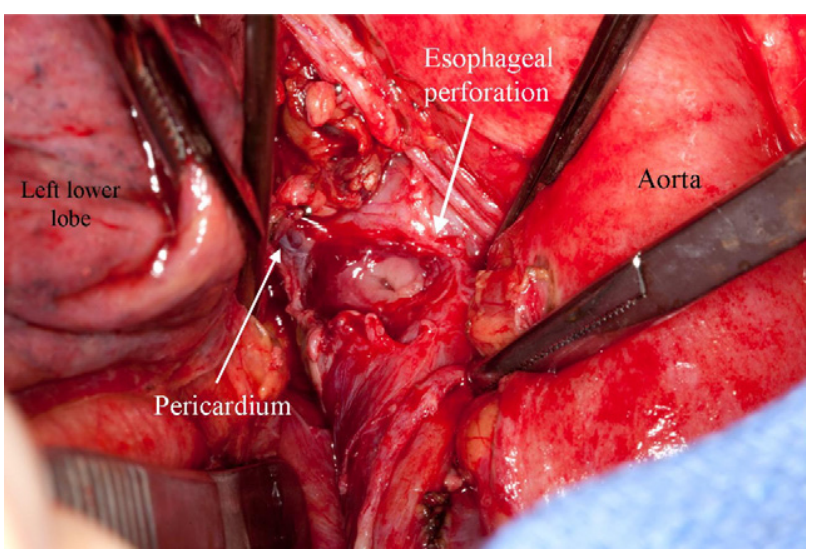

FIGURE 3. Intraoperative photograph showing the esophageal/pericardial perforation.

tamponade, pneumopericardium, or transient ischemic attacks in patients with a recent history of catheter ablation therapy should alert physicians to act promptly, involving the radiologists, cardiologists, and cardiothoracic surgeons because early aggressive intervention is the only factor that influences survival. ${ }^{16,26,33}$

Endoscopic therapies to evaluate the esophagus or to attempt stenting should be used with extreme caution and not until an atrioesophageal communication has been ruled out, because this can have lethal consequences due to the fact that carbon dioxide insufflation can cause irreversible massive air embolization.

In our patient, an atrial communication was ruled out clinically and by computed tomography scan, esophagogram, and echocardiogram; hence, the possibility to attempt endoluminal therapy. This proved to be inadequate initially due to stent migration. Despite adequate apposition of the stent, there was a persistent leak around the distal end. At that point surgery became the best therapeutic option for this patient.

Esophageal stents were used in 3 other patients reported in the literature, $, 26,33$ and that approach was successful in 2 patients. ${ }^{26,33}$ The timing of presentation of esophagopericardial fistula varies, ranging from 3 to 50 days with a mean of 19 days from the ablation therapy. Based on our literature review, we determined the most frequent presentation is a left atrioesophageal fistula, but pure esophagopericardial fistulae are also described. Sequelae from this complication are potentially severe and include transient or permanent neurologic events due to air embolism, sepsis, shock, and death if left untreated. ${ }^{7,23,33}$

Based on the literature, $88 \%$ of patients present or develop some form of neurologic event secondary to air embolism during their hospitalization that results in death in some cases ${ }^{10-12}$ (Table 1). Operative approaches used in the described cases ranged from median sternotomies to right or left thoracotomies. In our patient the swallow study 
TABLE 1. Literature review of esophageal complications from ablation therapy for atrial fibrillation

\begin{tabular}{|c|c|c|c|c|c|c|c|c|}
\hline Author & Year & $\begin{array}{l}\text { No. of } \\
\text { cases }\end{array}$ & Type & $\begin{array}{c}\text { Timing of } \\
\text { presentation }\end{array}$ & $\begin{array}{r}\text { Cerebral } \\
\text { embolism }\end{array}$ & Stent & Operation & Result \\
\hline Scanavacca, $\mathrm{M}^{15}$ & 2007 & 1 & AEF & 3 weeks & + & - & - & Death \\
\hline Pappone, $\mathrm{C}^{18}$ & 2004 & 2 & $\mathrm{AEF}$ & 3 days, 3 weeks & + & - & - & Embolic stroke, death \\
\hline Cummings, $\mathbf{J}^{19}$ & 2006 & 9 & $\mathrm{AEF}$ & 10-16 days & $+(8 / 9)$ & - & - & Death (9) \\
\hline Schley, $\mathrm{P}^{20}$ & 2006 & 1 & AEF & 26 days & + & - & - & Death \\
\hline Grubina, $\mathrm{R}^{21}$ & 2009 & 1 & PEF & 15 days & - & - & + Left thoracotomy, suture repair & Discharge on POD 11 \\
\hline Cazavet, $A^{9}$ & 2010 & 1 & $\mathrm{AEF}$ & 38 days & + & + failed & $\begin{array}{l}\text { + Left thoracotomy, suture repair, } \\
\text { pericardial patch }\end{array}$ & Discharge on POD 37 \\
\hline Gillinov, $\mathbf{M}^{17}$ & 2001 & 1 (i) & $\mathrm{AEF}$ & 9 days & + & - & Right thoracotomy, CPB & Death \\
\hline Warren, $S^{22}$ & 2007 & 1 & $\mathrm{AEF}$ & 25 days & + & - & + & Death \\
\hline Sonmez, $B^{23}$ & 2003 & 1 (i) & $\mathrm{AEF}$ & 22 days & + & - & + & Death \\
\hline Mohr, $\mathrm{FW}^{5}$ & 2002 & 3 (i) & $\mathrm{AEF}$ & 3-9 days & + & - & + & Death $1 / 3$ \\
\hline Preis, $\mathrm{O}^{24}$ & 2007 & 1 & $\mathrm{AEF}$ & 38 days & + & - & + & Discharge on POD 56 \\
\hline Ouchikhe, $A^{25}$ & 2008 & 1 & AEF & 21 days & + & - & - & Death \\
\hline Hazell, $\mathrm{W}^{26}$ & 2009 & 1 & $\mathrm{AEF}$ & 23 days & + & + & - & Death \\
\hline Malamis, $\mathrm{AP}^{27}$ & 2007 & 1 & $\mathrm{AEF}$ & 5 weeks & - & - & + & Death \\
\hline Doll, $\mathrm{N}^{16}$ & 2003 & 4 & $\mathrm{AEF}$ & 6-12 days & $2 / 4$ & - & $+4 / 4$ & Death $1 / 4$ \\
\hline Borchert, $\mathrm{B}^{28}$ & 2008 & 1 & $\mathrm{AEF}$ & 13 days & + & - & + & Death \\
\hline French, $\mathrm{KF}^{11}$ & 2011 & 1 & AEF & 50 days & + & - & - & Death \\
\hline Gilcrease, GW $^{29}$ & 2010 & 1 & AEF & 10 days & + & - & - & Death \\
\hline Siegel, $\mathrm{MO}^{30}$ & 2010 & 1 & $\mathrm{AEF}$ & 14 days & + & - & + & Survival \\
\hline Kandhar, $S^{31}$ & 2010 & 1 & $\mathrm{AEF}$ & 27 days & + & - & + & Survival \\
\hline Ghia, $\mathrm{KK}^{32}$ & 2009 & 6 & $\mathrm{AEF}$ & NA & + & - & NA & Death $5 / 6$ \\
\hline Dagres, $\mathrm{N}^{14}$ & 2006 & $5(4 i)$ & $\mathrm{AEF}$ & 8-28 days & $3 / 5$ & - & $3 / 5$ & Death $2 / 5$ \\
\hline Cappato, $\mathrm{R}^{7}$ & 2009 & 5 & $\mathrm{AEF}$ & 10-16 days & NA & NA & NA & Death $5 / 5$ \\
\hline
\end{tabular}

$A E F$, Atrioesophageal fistula; $P E F$, pericardio-esophageal fistula; $C P B$, cardiopulmonary bypass; $(i)$, intraoperative ablation; $N A$, not applicable; $P O D$, postoperative day.

showed a left-sided leak with a moderate left pleural effusion. This is why we chose a left-side surgical approach. In patients with atrioesophageal fistula it is important to be prepared to apply cardiopulmonary bypass if needed. Most of the time the esophagus can be repaired without the need for esophageal resection. Tissue interposition (eg, muscle, pericardium, and pleura) has been advocated by most authors for managing atrioesophageal fistulae as well as for managing esophageal perforations. ${ }^{9,14,15,34,35}$

Mortality has been reported between $75 \%$ and $83 \%{ }^{7}$ with many survivors remaining with neurologic sequelae. Probably there are other patients who die after catheter ablation therapy for atrial fibrillation without a known cause, maybe due to massive air embolism from an undiagnosed atrioesophageal fistula, making the real mortality unknown. The mechanism of fistula formation during ablation is not completely understood, because lesions, temperature, contact duration, and devices vary. The esophagus lies directly behind the left atrium and it is conceivable that thermal energy from the radiofrequency ablation can transmit through the atrial wall into the esophageal tissues. It has been hypothesized that reflux and acid contact with already injured esophageal mucosa leads to perforation and fistula.

Many reports from the electrophysiology literature recognize this potential complication and new techniques and maneuvers to minimize its occurrence have been reported, ${ }^{4,36}$ including esophageal temperature probes, endoscopic displacement of the esophagus during ablation, ${ }^{37}$ pre- and post-treatment with proton pump inhibitors, and aggressive correction of dehydration in attempt to ensure adequate esophageal blood flow for the theoretical heat sink effect benefit.

\section{CONCLUSIONS}

Increasing numbers of catheter-based ablation therapies will be performed in the future for atrial fibrillation. It is important that physicians are familiar with its potential complications. Atrioesophageal and pericardioesophageal fistulae are rare events but carry high morbidity and mortality. Early recognition and aggressive multidisciplinary surgical management are the only factors that can affect survival of an otherwise lethal complication.

\section{References}

1. Wann LS, Curtis AB, January CT, Ellenbogen KA, Lowe JE, Estes NA 3rd, et al. $2011 \mathrm{ACCF} / \mathrm{AHA} / \mathrm{HRS}$ focused update on the management of patients with atrial fibrillation (Updating the 2006 Guideline): a report of the American College of Cardiology Foundation/American Heart Association Task Force on Practice Guidelines. J Am Coll Cardiol. 2011;57:223-42.

2. Haissaguerre M, Jais P, Shah DC, Takahashi A, Hocini M, Quiniou G, et al. Spontaneous initiation of atrial fibrillation by ectopic beats originating in the pulmonary veins. N Engl J Med. 1998;339:659-66. 
3. Oral H. Catheter ablation for chronic atrial fibrillation. Heart Rhythm. 2007;4: 691-4.

4. Bunch TJ, Day JD. Moving away from esophageal injury during left atrial ablation. Heart rhythm: the official journal of the Heart Rhythm Society. 2009;6(3): 323-4.

5. Mohr FW, Fabricius AM, Falk V, Autoschbach R, Doll N, Von Oppell U, et al. Curative treatment of atrial fibrillation with intraoperative radiofrequency ablation: short-term and midterm results. J Thorac Cardiovasc Surg. 2002;123: 919-27.

6. Oral H, Pappone C, Chugh A, Good E, Bogun F, Pelosi F Jr, et al. Circumferential pulmonary-vein ablation for chronic atrial fibrillation. N Engl J Med. 2006;354: 934-41.

7. Cappato R, Calkins H, Chen SA, Davies W, Iesaka Y, Kalman J, et al. Prevalence and causes of fatal outcome in catheter ablation of atrial fibrillation. J Am Coll Cardiol. 2009;53:1798-803.

8. Belhassen B. A 1 per 1,000 mortality rate after catheter ablation of atrial fibrillation: an acceptable risk? J Am Coll Cardiol. 2009;53:1804-6.

9. Cazavet A, Muscari F, Marachet MA, Leobon B. Successful surgery for atrioesophageal fistula caused by transcatheter ablation of atrial fibrillation. $J$ Thorac Cardiovasc Surg. 2010;140:e43-5.

10. Finsterer J, Stollberger C, Pulgram T. Neurological manifestations of atrio-esophageal fistulas from left atrial ablation. Eur J Neurol. 2011; 18:1212-9.

11. French KF, Wold JJ, Hoesch RE, Ladyard HK. Cerebral air emboli with atrialesophageal fistula following atrial fibrillation ablation: a case report and review. Neurohospitalist. 2011;1:128-32.

12. Stollberger C, Pulgram T, Finsterer J. Neurological consequences of atrioesophageal fistula after radiofrequency ablation in atrial fibrillation. Arch Neurol. 2009; 66:884-7.

13. Daubert JC, Saxon L, Adamson PB, Auricchio A, Berger RD, Beshai JF, et al. 2012 EHRA/HRS expert consensus statement on cardiac resynchronization therapy in heart failure: implant and follow-up recommendations and management. Europace. 2012;14:1236-86.

14. Dagres N, Kottkamp H, Piorkowski C, Doll N, Mohr F, Horlitz M, et al. Rapid detection and successful treatment of esophageal perforation after radiofrequency ablation of atrial fibrillation: lessons from five cases. J Cardiovasc Electrophysiol. 2006;17:1213-5.

15. Scanavacca M, Hachul D, Sosa E. Atrioesophageal fistula-a dangerous complication of catheter ablation for atrial fibrillation. Nat Clin Pract Cardiovasc Med. 2007;4:578-9.

16. Doll N, Borger MA, Fabricius A, Stephan S, Gummert J, Mohr FW, et al. Esophageal perforation during left atrial radiofrequency ablation: is the risk too high? J Thorac Cardiovasc Surg. 2003;125:836-42.

17. Gillinov AM, Pettersson G, Rice TW. Esophageal injury during radiofrequency ablation for atrial fibrillation. J Thorac Cardiovasc Surg. 2001;122: 1239-40.

18. Pappone C, Oral H, Santinelli V, Vicedomini G, Lang CC, Manugso F, et al. Atrio-esophageal fistula as a complication of percutaneous transcatheter ablation of atrial fibrillation. Circulation. 2004;109:2724-6.

19. Cummings JE, Schweikert RA, Saliba WI, Burkhardt JD, Kilikasian F, Saad E, et al. Brief communication: atrial-esophageal fistulas after radiofrequency ablation. Ann Intern Med. 2006;144:572-4.

20. Schley P, Gulker H, Horlitz M. Atrio-oesophageal fistula following circumferential pulmonary vein ablation: verification of diagnosis with multislice computed tomography. Europace. 2006;8:189-90.
21. Grubina R, Cha YM, Bell MR, LJl Sinak, Asirvatham SJ. Pneumopericardium following radiofrequency ablation for atrial fibrillation: insights into the natural history of atrial esophageal fistula formation. J Cardiovasc Electrophysiol. 2010; 21:1046-9.

22. Warren S. Atrio-oesophageal fitula following pulmonary vein ablation. The 2 nd ISHNE Atrial Fibrillation Worldwide Internet Symposium 2007. Available from: http://af-symposium.grupoakros.com.ar/2007/clinicalcases.php. Accessed October $31,2012$.

23. Sonmez B, Demirsoy E, Yagan N, Unal M, Arbati H, Sener D, et al. A fatal complication due to radiofrequency ablation for atrial fibrillation: atrio-esophageal fistula. Ann Thorac Surg. 2003;76:281-3.

24. Preis O, Digumarthy SR, Wright CD, Shepard JA. Atrioesophageal fistula after catheter pulmonary venous ablation for atrial fibrillation: imaging features. J Thorac Imaging. 2007;22:283-5.

25. Ouchikhe A, Maindivide J, le Bivic JL, Roux L, Vincent JF. [Atrio-oesophagea fistula after radiofrequency ablation: predominant neurological symptoms]. Ann Fr Anesth Reanim. 2008;27:499-501.

26. Hazell W, Heaven D, Kazemi A, Fourie D. Atrio-oesophageal fistula: an emergent complication of radiofrequency ablation. Emerg Med Australas. 2009;21: 329-32.

27. Malamis AP, Kirshenbaum KJ, Nadimpalli S. CT radiographic findings: atrioesophageal fistula after transcatheter percutaneous ablation of atrial fibrillation. J Thorac Imaging. 2007;22:188-91.

28. Borchert B, Lawrenz T, Hansky B, Stellbrink C. Lethal atrioesophageal fistula after pulmonary vein isolation using high-intensity focused ultrasound (HIFU) Heart Rhythm. 2008;5:145-8.

29. Gilcrease GW, Stein JB. A delayed case of fatal atrioesophageal fistula following radiofrequency ablation for atrial fibrillation. J Cardiovasc Electrophysiol. 2010; 21:708-11.

30. Siegel TR, Douglass M. Perforation of an ileostomy by a retained percutaneous endoscopic gastrostomy (PEG) tube bumper. Surg Endoscopy. 2004; 18:348.

31. Khandhar SS, Nitzschke S, Ad N. Left atrioesophageal fistula following catheter ablation for atrial fibrillation: off-bypass, primary repair using an extrapericardial approach. J Thorac Cardiovasc Surg. 2010;139:507-9.

32. Ghia KK, Chugh A, Pelosi F, Jongnarangsin K, Bogun F, Morady F, et al. A nationwide survey on the prevalence of atrioesophageal fistula after left atrial radiofrequency catheter ablation. J Interv Card Electrophysiol. 2009; 24:33-6.

33. Bunch TJ, Nelson J, Foley T, Allison S, Crandall BG, Osborn JS, et al Temporary esophageal stenting allows healing of esophageal perforations following atrial fibrillation ablation procedures. J Cardiovasc Elecrophysiol. 2006; 17:435-9.

34. Gillinov AM, McCarthy PM, Pettersson G, Lytle BW, Rice TW. Esophageal perforation during left atrial radiofrequency ablation: is the risk too high? J Thorac Cardiovasc Surg. 2003;126:1661-2. author reply 1662.

35. Fell SC. Chapter 73. Esophageal perforations. In: Fell SC, ed. Pearson's thoracic and esophageal surgery. vol 2, 3rd ed. London, England: Churchill Livingstone; 2010.

36. Bunch TJ, Day JD. Novel ablative approach for atrial fibrillation to decrease risk of esophageal injury. Heart Rhythm. 2008;5:624-7.

37. Chugh A, Rubenstein J, Good E, Ebinger M, Jongnarangsin K Fortino J, et al. Mechanical displacement of the esophagus in patients undergoing left atrial ablation of atrial fibrillation. Heart Rhythm. $2009 ; 6(3): 319-22$. 